ARTICLE

https://doi.org/10.1038/s41467-019-09832-4

\title{
Homo- and heterodehydrocoupling of phosphines mediated by alkali metal catalysts
}

Lipeng Wu (1) 1,2,6, Vincent T. Annibale (1) 1,6, Haijun Jiao ${ }^{3}$, Adam Brookfield ${ }^{4}$, David Collison ${ }^{4}$ \& Ian Manners ${ }^{1,5}$

Catalytic chemistry that involves the activation and transformation of main group substrates is relatively undeveloped and current examples are generally mediated by expensive transition metal species. Herein, we describe the use of inexpensive and readily available $t B u O K$ as a catalyst for $\mathrm{P}-\mathrm{P}$ and $\mathrm{P}-\mathrm{E}(\mathrm{E}=\mathrm{O}, \mathrm{S}$, or $\mathrm{N})$ bond formation. Catalytic quantities of $t \mathrm{BuOK}$ in the presence of imine, azobenzene hydrogen acceptors, or a stoichiometric amount of $t B u O K$ with hydrazobenzene, allow efficient homodehydrocoupling of phosphines under mild conditions (e.g. $25^{\circ} \mathrm{C}$ and $<5 \mathrm{~min}$ ). Further studies demonstrate that the hydrogen acceptors play an intimate mechanistic role. We also show that our $t B u O K$ catalysed methodology is general for the heterodehydrocoupling of phosphines with alcohols, thiols and amines to generate a range of potentially useful products containing $\mathrm{P}-\mathrm{O}, \mathrm{P}-\mathrm{S}$, or $\mathrm{P}-\mathrm{N}$ bonds.

\footnotetext{
${ }^{1}$ School of Chemistry, University of Bristol, Cantock's Close, Bristol BS8 1TS, UK. ${ }^{2}$ State Key Laboratory for Oxo Synthesis and Selective Oxidation, Suzhou Research Institute of Lanzhou Institute of Chemical Physics, CAS, 730000 Lanzhou, P. R. China. ${ }^{3}$ Leibniz-Institut für Katalyse e. V, Albert-Einstein-Straße 29a, 18059 Rostock, Germany. ${ }^{4}$ The School of Chemistry and the Photon Science Institute, The University of Manchester, Oxford Road, Manchester M13 9PL, UK. ${ }^{5}$ Department of Chemistry, University of Victoria, Victoria, BC V8W 3V6, Canada. ${ }^{6}$ These authors contributed equally: Lipeng Wu, Vincent T. Annibale. Correspondence and requests for materials should be addressed to I.M. (email: imanners@uvic.ca)
} 
W hen compared to the traditional stoichiometric salt metathesis and reductive coupling reactions that still dominate the formation of element-element bonds in main group chemistry, catalytic methods represent a highly attractive alternative synthetic approach ${ }^{1-7}$. For example, substantial advances have been made in catalytic dehydrocoupling of p-block substrates to form both homonuclear (E-E) or heteronuclear $\left(\mathrm{E}-\mathrm{E}^{\prime}\right)$ bonds $\left(\mathrm{E}, \mathrm{E}^{\prime}=p\right.$-block element). However, most of the current catalysts in use are based on precious transition metals such as $\mathrm{Rh}^{8-11}, \mathrm{Ir}^{12-15}$ and $\mathrm{Ru}^{16}$ raising concerns about their high price as a result of their low natural abundance and their presence as potentially toxic residues in polymer products $^{17-19}$. Although significant progress has been made in terms of the use of earth abundant metals such as $\mathrm{Zr}^{20-22}, \mathrm{Fe}^{23,24}$ and $\mathrm{Ni}^{25,26}$, the development of transition metal-free dehydrocoupling catalysts also offers considerable potential. For example, recent reports describe advances concerning the use of main group species such as [(Dipp-nacnac) $\left.\mathrm{Mg}^{n} \mathrm{Bu}\right]_{2}{ }^{27}, \mathrm{Al}\left(\mathrm{NMe}_{2}\right)_{3}{ }^{28}$ and $\mathrm{B}\left(\mathrm{C}_{6} \mathrm{~F}_{5}\right)_{3}{ }^{29}$, especially in the areas of $\mathrm{N}-\mathrm{B}$ and $\mathrm{P}-\mathrm{Si}$ bond formation. Rare examples of the use of alkali metal reagents such as $\mathrm{KN}\left(\mathrm{SiMe}_{3}\right)_{2}{ }^{30}, 1$-lithium-2-tert-butyl-1,2-dihydropyridine ${ }^{31}$, or group 1 salts containing a carbazolido NNN pincer ligand ${ }^{32}$ for the dehydrocoupling of $\mathrm{Me}_{2} \mathrm{NH} \bullet \mathrm{BH}_{3}$ to form $\left[\mathrm{Me}_{2} \mathrm{NBH}_{2}\right]_{2}$ have also been described.

Molecular compounds containing P-P bonds have numerous applications in coordination $7,33,34$ and synthetic chemistry $29,35-37$, and diphosphines readily react with alkenes or alkynes to form bidentate ligands ${ }^{38-40}$. Probably because of the potential catalyst deactivation due to unproductive phosphine coordination, only few transition metal catalysts ( $\mathrm{Zr}, \mathrm{Rh}$ ) have been successfully applied for P-P bond formation via catalytic dehydrocoupling ${ }^{3,7}$. Furthermore, in most cases, relatively high temperatures $\left(110-140^{\circ} \mathrm{C}\right)$ and long reaction times $(3-4$ days $)$ were required ${ }^{2} 41-44$. Recently, transition metal-free catalysts $\left(\mathrm{C}_{5} \mathrm{Me}_{5}\right)_{2} \mathrm{SnCl}_{2}{ }^{45}, \mathrm{~B}\left(p-\mathrm{C}_{6} \mathrm{~F}_{4} \mathrm{H}\right)_{3}{ }^{46}$ and stoichiometric reagents, namely lithium chloride carbenoids ${ }^{47}$ and $N$-heterocyclic carbenes $^{48}$, have also been reported to mediate phosphine dehydrocoupling although either harsh reaction conditions, long reaction times, or non-commercially available reagents were still required (Fig. 1a).

In addition to species containing $\mathrm{P}-\mathrm{P}$ bonds, compounds containing $\mathrm{P}-\mathrm{O}, \mathrm{P}-\mathrm{S}$ and $\mathrm{P}-\mathrm{N}$ bonds also have widespread importance in catalysis, organic synthesis, and in biochemistry and agrochemistry 49,50 . Apart from an example of heterodehydrocoupling of phosphines with protic substrates $(\mathrm{PhS}-\mathrm{H})$ to form P-S bonds mediated by in situ generated rhodium phosphido complexes at $110^{\circ} \mathrm{C}$ (Fig. $\left.1 b\right)^{2}$, catalytic heterodehydrocoupling of phosphines with other protic substrates is unexplored. In particular, the development of a cost-effective, general, and practical transition metal-free catalytic homodehydrocoupling and heterodehydrocoupling of phosphines is highly desirable. Herein, we report our findings on the use of inexpensive and commercially available reagent $t \mathrm{BuOK}$ as a general catalyst for dehydrocoupling reactions involving phosphines and the formation of $\mathrm{P}-\mathrm{P}, \mathrm{P}-\mathrm{O}, \mathrm{P}-\mathrm{N}$ and $\mathrm{P}-\mathrm{S}$ bonds (Fig. 1c).

\section{Results}

Dehydrocoupling of phosphines. Phosphorus and hydrogen possess similar Pauling electronegativities leading to only a weak polarisation for $\mathrm{P}-\mathrm{H}$ bonds. As strong Lewis acids such as $\mathrm{B}(p-$ $\left.\mathrm{C}_{6} \mathrm{~F}_{4} \mathrm{H}\right)_{3}$ have been shown to dehydrocouple phosphines $\left(\mathrm{R}^{1} \mathrm{R}^{2} \mathrm{PH}, \mathrm{R}^{2}=\mathrm{R}^{1}\right.$ or $\left.\mathrm{H}\right)$ via a mechanism that involves sequential hydride and proton removal from phosphorus ${ }^{46}$, we rationalised that a strong base might be able to mediate the same process. a

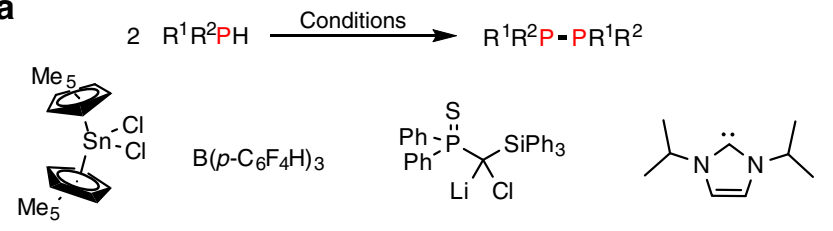
$10 \mathrm{~mol} \%, 60{ }^{\circ} \mathrm{C} \quad 10 \mathrm{~mol} \%, 130{ }^{\circ} \mathrm{C} \quad 50 \mathrm{~mol} \%,-78$ to $25^{\circ} \mathrm{C} \quad 200 \mathrm{~mol} \%, 140{ }^{\circ} \mathrm{C}$ 4 days $\quad 5$ days $1 \mathrm{~h} \quad 3$ days

b

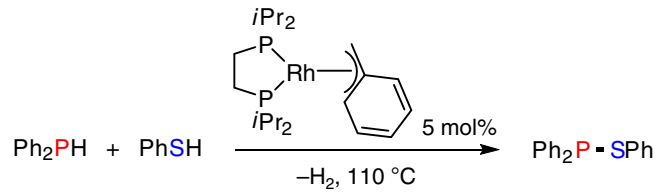

C

This work

$$
\begin{gathered}
2 \mathrm{R}^{1} \mathrm{R}^{2} \mathrm{PH} \frac{\text { cat. } t \text { BuOK }}{1 \text { equiv. } \mathrm{HA}}-\mathrm{R}^{1} \mathrm{R}^{2} \mathrm{P}-\mathrm{PR}^{1} \mathrm{R}^{2} \\
\mathrm{R}^{1} \mathrm{R}^{2} \mathrm{PH}+\mathrm{R}^{3} \mathrm{E} \mathrm{H}_{\mathrm{n}} \frac{\text { cat. } \mathrm{BuOK}}{1 \text { equiv. } \mathrm{HA}}-\mathrm{R}^{1} \mathrm{R}^{2} \mathrm{P}-\mathrm{EH}_{\mathrm{n}-1} \mathrm{R}^{3} \\
\mathrm{HA}=\text { hydrogen acceptors, } \mathrm{R}^{2}=\mathrm{R}^{1} \text { or } \mathrm{H}, n=1,2 ; \mathrm{E}=\mathrm{N}, \mathrm{O}, \mathrm{S}
\end{gathered}
$$

Fig. 1 Developed catalysts for P-P and P-E bond formation. a Main group catalysts and conditions for the homodehydrocoupling of phosphines. b Heterodehydrocoupling of diphenylphosphine with thiophenol by in situ generated rhodium phosphido complexes. c Our current work using tBuOK as the catalyst for the homo- and heterodehydrocoupling of phosphines

Based on the recently revealed, highly versatile role of $t \mathrm{BuOK}$ in initiating $\mathrm{C}-\mathrm{C}^{51,52}, \mathrm{C}-\mathrm{Si},{ }^{53} \mathrm{Si}-\mathrm{O}^{54}$ and $\mathrm{C}-\mathrm{N}$ bond formation, ${ }^{55}$ we studied the use of $t \mathrm{BuOK}$ as a catalyst for the homodehydrocoupling of phosphines. Initially, we chose diphenylphosphine (1a) as a model substrate and the reaction was attempted with $0.1 \mathrm{mmol}$ of $\mathbf{1 a}$ with $10 \mathrm{~mol} \% t \mathrm{BuOK}$ in $0.5 \mathrm{~mL}$ THF at $130^{\circ} \mathrm{C}$. After $16 \mathrm{~h}$ no reaction had taken place. Given the recent examples of the introduction of a hydrogen acceptor (HA) for the promotion of dehydrocoupling reactions $s^{29,46,56,57}$, we then explored the use of different types of $\mathbf{H A}$ for this reaction with dramatically different results (Fig. 2a and Supplementary Table 1). HA-1 to HA-5 were most effective: for example, benzophenone (HA-1) led to 86\% conversion of 1a and the formation of $\mathbf{2 a}$ in $47 \%$ yield whereas trans-stilbene (HA-3) gave full conversion of $1 \mathrm{a}$ accompanied by the production of $2 \mathrm{a}$ in $69 \%$ yield. In the latter case residual la was found to be converted to the hydrophosphination product. Most impressively, with the addition of $N$-benzylideneaniline (HA-5) we achieved $>99 \%$ conversion of $\mathbf{1 a}$ with the formation of $\mathbf{2 a}$ in $92 \%$ yield. Computationally, the parent dehydrocoupling reaction of 2 equiv. 1a to $2 \mathbf{a}$ and $\mathrm{H}_{2}$ in the absence of an HA was thermodynamically uphill by $2.64 \mathrm{kcal} \mathrm{mol}^{-1}$, and likely possesses a significant kinetic barrier. The dehydrocoupling reactions with added HA-1 to HA5 were all calculated to be thermodynamically exergonic (see Supplementary Discussion and Supplementary Data 1,2 in the Supplementary Information).

With HA-5, efforts to perform the reaction under milder conditions were made using different bases, temperatures, and catalyst loadings (Supplementary Tables 2-5). Notably, with 0.01 mmol of $t \mathrm{BuOK}(10 \mathrm{~mol} \%)$ and $0.1 \mathrm{mmol}$ of $\mathbf{H A}-5,82 \%$ yield of 2a was obtained after $64 \mathrm{~h}$ at $25^{\circ} \mathrm{C}$ (Supplementary Table 2, entry 4). Even with $2.5 \mathrm{~mol} \% t \mathrm{BuOK}$ at $60^{\circ} \mathrm{C}$, we could still achieve $85 \%$ yield after $24 \mathrm{~h}$ (Supplementary Table 2, entry 6). It is worth noting that $10 \mathrm{~mol} \%$ of different alkali metal tert-butoxides were 
a
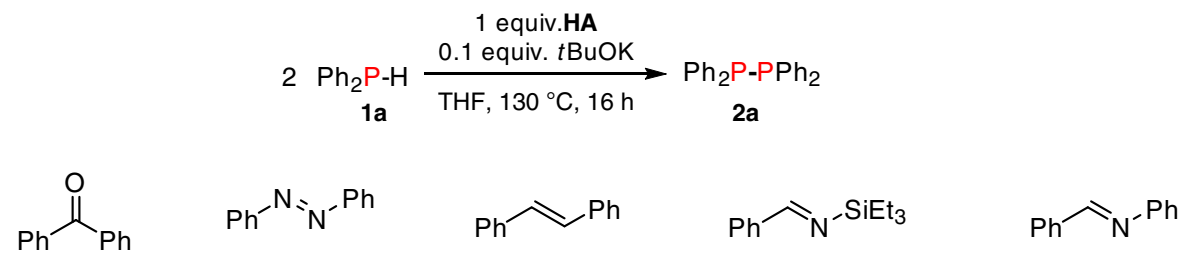

HA-1

HA-2

HA-3

HA-4

HA-5

2a yield: $\quad 47 \%$

$17 \%$

$69 \%$

$57 \%$

$92 \%$

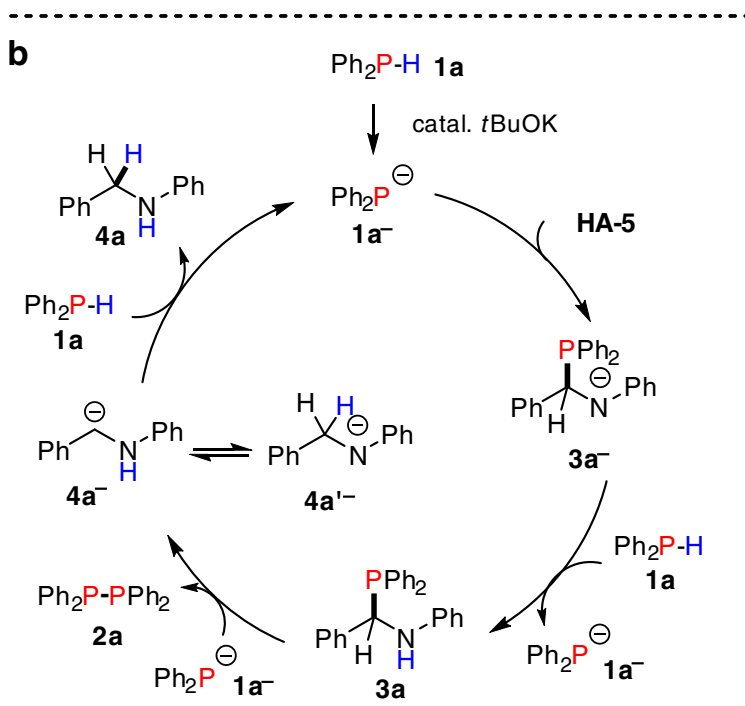

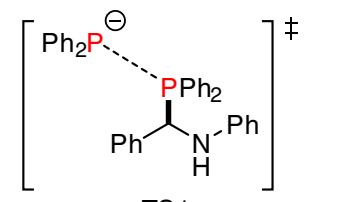

TS1

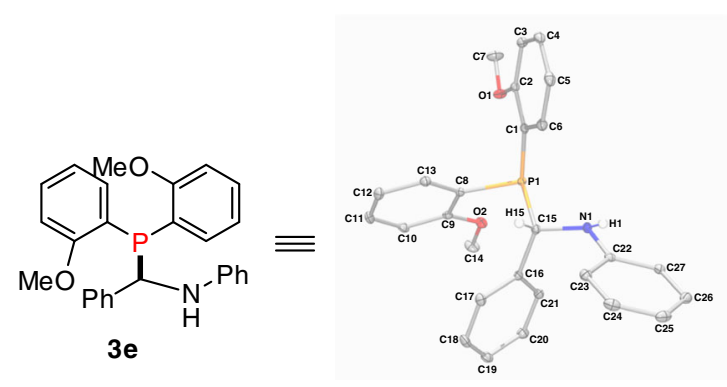<smiles></smiles>

TS2

c

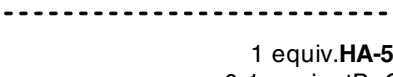

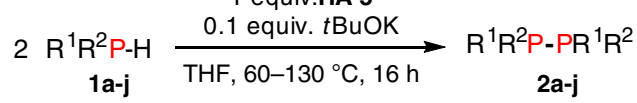

$R^{2}=R^{1}$ or $H$<smiles>CCc1ccc(P(C)P(C)c2ccc(C(C)C)cc2)cc1</smiles>

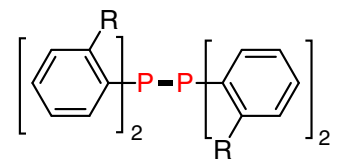

$\mathrm{R}=\mathrm{H}$ 2a, yield: $95 \%(90)^{\mathrm{a}}$

$\mathrm{R}=\mathrm{OMe}, \mathbf{2 b}$ yield: $75 \%(71)^{\mathrm{c}}$

$\mathrm{R}=$ OMe $2 \mathrm{e}$, yield: $6 \%^{\mathrm{C}}$

$\mathrm{R}=\mathrm{F} 2 \mathrm{c}$, yield: $46 \%^{\mathrm{c}}$

$\mathrm{R}=\mathrm{Cl}$ 2d, yield: $55 \%^{\mathrm{c}}$

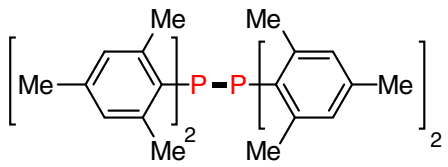

$2 \mathrm{~h}$ yield: $\mathbf{0}^{\mathrm{c}}$

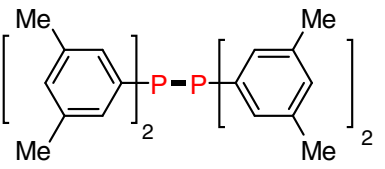

$2 \mathrm{~g}$ yield: $76 \%(70)^{\mathrm{a}}$

R = Me 2f, yield: $76 \%(73)^{b}$ 
screened as catalysts for the dehydrocoupling reaction with added HA-5 where the activity followed the order of $\mathrm{K}>\mathrm{Na}>\mathrm{Li}$ (Supplementary Table 4). We then chose $60^{\circ} \mathrm{C}$ and $10 \mathrm{~mol} \%$ $t \mathrm{BuOK}$ as the reaction conditions (which gave a $95 \%$ yield of $2 \mathrm{a}$ after $8 \mathrm{~h}$, Supplementary Table 4) for further mechanistic studies. It is known that $\mathrm{P}-\mathrm{H}$ bonds can be activated by strong bases to initiate the subsequent hydrophosphination of the $\mathrm{C}=\mathrm{N}$ or $\mathrm{C}=\mathrm{C}$ double bond ${ }^{58-60}$. We explored the potential role of the hydrophosphination product from 1a and HA-5 and carried out several control experiments; the results are summarised in Supplementary Fig. 1. Heating 1a or a mixture of 1a and HA-5 at $60^{\circ} \mathrm{C}$ in THF gave no reaction after $8 \mathrm{~h}$ (Supplementary Fig. 1, Eqs. 1-2). When $10 \mathrm{~mol} \%$ of $t \mathrm{BuOK}$ was added to the THF solution containing $1 \mathrm{a}$ and HA-5, the rapid emergence of a new peak at $3.3 \mathrm{ppm}$ in the ${ }^{31} \mathrm{P}\left\{{ }^{1} \mathrm{H}\right\}$ nuclear magnetic resonance (NMR) spectrum was observed (Supplementary Fig. 2). This was assigned to the hydrophosphination adduct $\mathbf{3 a}$ upon synthesis and subsequent characterisation of a sample of this species (Supplementary Fig. 1, Eq. 3). After 8 h compound 3a was quantitatively converted to a mixture of the homodehydrocoupling product $\mathbf{2 a}$, and $N$-benzylaniline $\mathbf{4 a}$, and HA-5 in a 1:1:1 molar ratio (Supplementary Fig. 1, Eq. 5 and Supplementary Figs. 3-5). Monitoring the transformation of 3a to $2 \mathbf{a}$ at $30 \mathrm{~min}$ intervals showed that no other $P$-containing species were involved, except for minor amounts of 5a by-product which were also observed (Supplementary Fig. 6). It is worth noting that 3a is in equilibrium with HA-5 and 1a (Supplementary Fig. 1, Eq. 4), and that the transformation of $\mathbf{3 a}$ to the 1:1:1 mixture of 2a, 4a, and HA-5 requires the presence of the $t \mathrm{BuOK}$ catalyst (Supplementary Fig. 1, Eq. 5) ${ }^{61}$. Our experiments suggest that $\mathbf{3 a}$ is the key intermediate for the homodehydrocoupling of $\mathbf{1 a}$.

Based on the results of the stepwise experiments we proposed the reaction mechanism outlined in Fig. 2b. Firstly, 1a is deprotonated by $t \mathrm{BuOK}$ to form diphenylphosphide $\mathbf{1 a}^{-}$. This activation facilitates the addition of $\mathbf{1 a}$ to $\mathbf{H A - 5}$ to form the hydrophosphination adduct 3a. Based on the knowledge that $\mathrm{S}_{\mathrm{N}} 2$ reactions at phosphorus are possible ${ }^{62-64}$ and similar halophilic reactions exist, we anticipated that hydrophosphination adduct $\mathbf{3 a}$ is attacked by anionic $1 \mathbf{a}^{-}$at the phosphorus centre through a $\mathrm{S}_{\mathrm{N}} 2$-type of reaction (TS1) which eventually yields $2 \mathrm{a}$. Similarly, 3a could be attacked by the $t \mathrm{BuO}^{-}$anion (TS2) which leads to the side product $\mathrm{Ph}_{2} \mathrm{P}-\mathrm{O} t \mathrm{Bu}$ 5a detected by ${ }^{31} \mathrm{P}\left\{{ }^{1} \mathrm{H}\right\} \mathrm{NMR}$ as a peak at $86.9 \mathrm{ppm}$ (Supplementary Fig. 6). Here we propose a carbanionic leaving group $\left(\mathbf{4 a}^{-}\right)$which may tautomerise to the amide anion $\left(\mathbf{4} \mathbf{a}^{\prime}\right)$, which can also deprotonate $\mathbf{1 a}$ and regenerate $1 \mathbf{a}^{-}$and close the catalytic cycle. Similar transient carbanionic species are also proposed in Brook rearrangements of silylated amines in the presence of a catalytic amount of base ${ }^{65,66}$, and carbanionic leaving groups are also known in reactions of phosphine oxides with organometallic reagents ${ }^{67}$. Another possibility is following the nucleophilic attack of the phosphorus of $\mathbf{3} \mathbf{a}$ by an anion such as $1 \mathbf{a}^{-}$or $t \mathrm{BuO}^{-}$there may be a process in which the $\mathrm{P}-\mathrm{C}$ bond cleavage process is accompanied by protonation by an incoming protic substrate at the incipiently generated and partially carbanionic site.

When HA-5 was substituted at the para-position of the benzylidene phenyl group with an electron-withdrawing group $(-\mathrm{COOMe})$ the initial reaction rate was substantially increased, on the other hand with an electron-donating $(-\mathrm{Me})$ group the initial reaction rate was much slower (Supplementary Fig. 7). These kinetic observations provide further support for the proposed reaction mechanism described in Fig. $2 b$ as an electronwithdrawing group should stabilise the anionic leaving group $4 a^{-}$.

The substrate generality for the reaction was then studied (Fig. 2c). With diphenyl phosphine (1a) as substrate, a 95\% yield of the dehydrocoupling product $\mathbf{2 a}$ could be obtained. In the case of para-methoxy-substituted secondary phosphines, a 75\% yield of $\mathbf{2 b}$ was gained. For chloro- and fluoro-substituted phosphines, more moderate yields were observed for $\mathbf{2 c}$ and $\mathbf{2 d}$, perhaps due to the side reactions involving $\mathrm{C}-\mathrm{F}$ and $\mathrm{C}-\mathrm{Cl}$ bonds such as dehalogenation ${ }^{68,69}$. When bis(ortho-methoxyphenyl) phosphine was used we can only obtain $6 \%$ of the homodehydrocoupling product $2 \mathrm{e}$ due to the existence of a large quantity of intermediate $\mathbf{3 e}$, which was crystallographically characterised (Fig. 2b, Supplementary Table 7), which suggests that the sterics of the substituents at phosphorus play a key role and is consistent with our proposed mechanism involving both $P$-based nucleophiles and electrophiles. Thus, for example, with less bulky metamethylphenyl substituents on phosphorus a $76 \%$ yield of $\mathbf{2 g}$ was observed. On the other hand, the presence of a bulkier mesityl substituent (as in $\mathbf{2 h}$ ) totally suppressed the hydrophosphination and the subsequent dehydrocoupling reaction. We also extended our protocol to primary phosphines and found that phenylphosphine was selectively transformed into 5-membered cyclic ring $[\mathrm{PhP}]_{5} 2 \mathbf{i}$ in $63 \%$ yield. Interestingly, when the aliphatic primary phosphine cyclohexylphosphine was used, cyclic $\mathbf{2 j}$, which contains a 4 -membered ring, was produced in $29 \%$ yield and this species was characterised crystallographically (Fig. 2c, Supplementary Table 7).

Based on our proposed mechanism in Fig. 2b, the high conversion of 1a but lower yield of diphosphine $\mathbf{2} \mathbf{a}$ for the cases of HA-3 and HA-4 can be explained by the presence of unconverted hydrophosphination intermediate (Supplementary Figs. 10, 11). However, in the case of azobenzene (HA-2), where the yield of $\mathbf{2 a}$ is particularly low (17\%), no hydrophosphination product was detected at $130{ }^{\circ} \mathrm{C}$ in THF over $16 \mathrm{~h}$. Instead, in addition to the peak for $\mathbf{2 a}$, two further peaks were present in the ${ }^{31} \mathrm{P}\left\{{ }^{1} \mathrm{H}\right\}$ NMR spectrum and these were assigned to $\mathrm{Ph}_{2} \mathrm{P}-\mathrm{O} t \mathrm{Bu}$ (5a, 86.9 ppm) and $\mathrm{Ph}_{2} \mathrm{P}-\mathrm{NHPh}(6 \mathbf{a}, 26.9 \mathrm{ppm})$ (Supplementary Fig. 9). We then explored whether the reaction using HA-2 could be further optimised (Supplementary Table 6). Remarkably, on lowering the reaction temperature from 130 to $25^{\circ} \mathrm{C}$ while using $10 \mathrm{~mol} \%$ of $t \mathrm{BuOK}$ resulted in the formation of $2 \mathbf{a}$ in $75 \%$ yield within 5 min (Supplementary Table 6, entry 1).

Low-temperature ${ }^{31} \mathrm{P}$ NMR spectroscopy was performed in THF to provide some initial insight into the reaction (Supplementary Fig. 13). Gradually increasing the temperature from $-60^{\circ} \mathrm{C}$ to room temperature clearly showed the decay of 1a and growth of the diphosphine 2a. At $25^{\circ} \mathrm{C}$, two additional peaks at $60.8 \mathrm{ppm}$ (hydrophosphination adduct $\mathrm{Ph}_{2} \mathrm{P}-\mathrm{N}(\mathrm{Ph}$ )$\mathrm{NHPh}, 7 \mathbf{a})^{70}$ and $86.9 \mathrm{ppm}\left(\mathrm{Ph}_{2} \mathrm{P}-\mathrm{O} t \mathrm{Bu}, 5 \mathbf{5}\right)$ appeared. Further experiments showed that when the stoichiometry of the reaction was changed and a mixture composed of 2 equiv. of $1 \mathrm{a}$ and 1 equiv. of HA-2 was treated using $10 \mathrm{~mol} \%$ of $t \mathrm{BuOK}$ resulted in complete conversion to a 1:1 mixture of $\mathbf{2 a}$ and hydrazobenzene within $5 \mathrm{~min}$ at $25^{\circ} \mathrm{C}$ (Fig. 3a, Supplementary Figs. 14 and 15).

A series of stoichiometric and catalytic reactions were performed in an attempt to determine potential active species present over the course of catalysis. In the 1:1 stoichiometric reaction of orange azobenzene (HA-2) with $t \mathrm{BuOK}$ in THF- $d_{8}$ a dark brown reaction mixture resulted for which analysis by ${ }^{1} \mathrm{H}$ and ${ }^{13} \mathrm{C}\left\{{ }^{1} \mathrm{H}\right\}$ NMR revealed the presence of only unreacted diamagnetic HA-2 and $t \mathrm{BuOK}$ (Supplementary Fig. 16). However a solution-state EPR spectrum in THF/2-Me-THF (20:1) at $25^{\circ} \mathrm{C}$ revealed a signal at approximately $g=2$ which is characteristic of an organic radical and shows a hyperfine structure consistent with the previously reported azobenzenyl radical anion $\mathrm{K}$ [PhNNPh] (Fig. 3b, Supplementary Fig. 16) ${ }^{71,72}$. The 1:1 stoichiometric reaction of $\mathbf{H A - 2}$ with $\mathrm{K}\left[\mathrm{PPh}_{2}\right]\left(\mathbf{1 a}^{-}\right)$also yielded a deep 
a

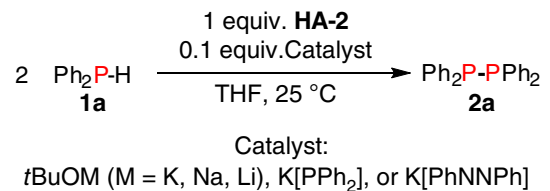

b

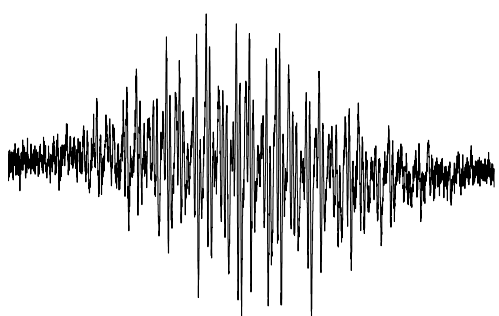

3500

$\begin{array}{lll}3510 & 3520 & 3530 \\ \text { Field (G) } & & \end{array}$

C

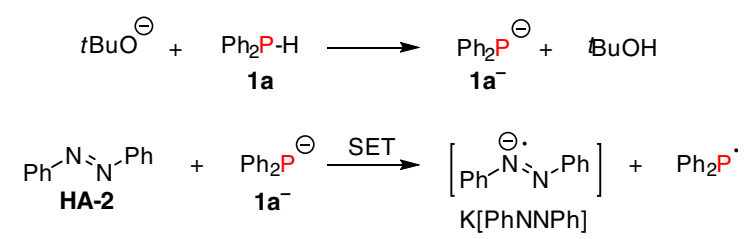

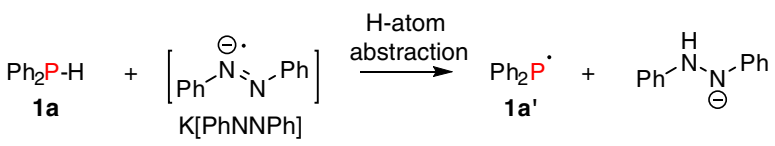

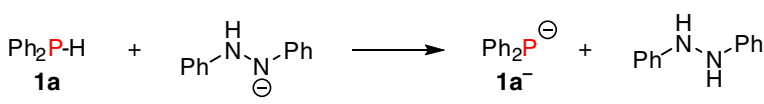

$$
\begin{aligned}
& \underset{\mathrm{Ph}_{2} \mathrm{P}^{\cdot}}{\mathbf{1 \mathbf { a } ^ { \prime }}}+\underset{\mathbf{1}}{\mathrm{Ph}_{2} \mathrm{P}^{\prime}} \stackrel{\substack{\text { Radical } \\
\text { coupling }}}{\longrightarrow} \underset{\mathbf{2 a}}{\mathrm{Ph}_{2} \mathrm{P}-\mathrm{PPh}_{2}}
\end{aligned}
$$

Fig. 3 Dehydrocoupling of $\mathbf{1 a}$ in presence of azobenzene (HA-2). a Homodehydrocoupling of $\mathbf{1 a}$ catalysed by $\operatorname{tBuOM}(\mathrm{M}=\mathrm{K}, \mathrm{Na}, \mathrm{Li}), \mathrm{K}\left[\mathrm{PPh}_{2}\right]$ $\left(\mathbf{1} \mathbf{a}^{-}\right)$, or $\mathrm{K}[\mathrm{PhNNPh}]$ at $25^{\circ} \mathrm{C}$. $\mathbf{b}$ X-band EPR spectrum of $\mathrm{K}$ [PhNNPh] in THF/2-Me-THF (20:1) generated in the 1:1 stoichiometric reaction of HA-2 with $t$ BuOK. c Proposed radical chain mechanism for dehydrocoupling of $\mathbf{1 a}$ to $\mathbf{2 a}$ mediated by in situ generated radical anion K[PhNNPh]

brown solution however by ${ }^{1} \mathrm{H}$ and ${ }^{31} \mathrm{P}\left\{{ }^{1} \mathrm{H}\right\}$ NMR the only diamagnetic species observed was $\mathbf{2 a}$, as HA-2 was fully converted to its radical anion $\mathrm{K}[\mathrm{PhNNPh}]$, which was also observed by EPR (Supplementary Fig. 17).

The radical anion $\mathrm{K}[\mathrm{PhNNPh}]$ could also be independently prepared from potassium metal and HA-2 for use in further studies on its role as a catalyst (Supplementary Fig. 18). Upon the addition of $10 \mathrm{~mol} \% \mathrm{~K}[\mathrm{PhNNPh}]$ to a 1:1 stoichiometric mixture of $\mathbf{1} \mathbf{a}$ and HA-2 gave approximately a 1:1 mixture of $7 \mathbf{a}$ and $2 \mathbf{a}$ by ${ }^{31} \mathrm{P}\left\{{ }^{1} \mathrm{H}\right\}$ NMR spectroscopy along with hydrazobenzene (Supplementary Fig. 19). Remarkably, treatment of a mixture of 2 equiv. of $1 \mathbf{a}$ and 1 equiv. of HA-2 in THF with either $10 \mathrm{~mol} \% \mathbf{1 a}^{-}$or independently synthesised $\mathrm{K}[\mathrm{PhNNPh}]$ resulted in complete conversion to a 1:1 mixture of $\mathbf{2 a}$ and hydrazobenzene within $5 \mathrm{~min}$ at $25^{\circ} \mathrm{C}$ (Fig. 3a, Supplementary Figs. 14 and 15), analogous to the results obtained when $10 \mathrm{~mol} \% t \mathrm{BuOK}$ was used. The K[PhNNPh] radical anion was also observed by EPR spectroscopy in the reaction of HA-2 with $t \mathrm{BuOK}$ and 0.5 equiv. of the substrate 1a (Supplementary Fig. 20).
In addition, the use of $10 \mathrm{~mol} \% \mathrm{tBuONa}$ also resulted in complete conversion of 2 equiv. of 1 a and 1 equiv. of HA-2 within $5 \mathrm{~min}$ at $25^{\circ} \mathrm{C}$, while $t \mathrm{BuOLi}$ was significantly slower requiring $6 \mathrm{~h}$ at $25^{\circ} \mathrm{C}$ to reach full conversion, likely due to the poor solubility of $t \mathrm{BuOLi}$ in THF (Fig. 3a). While both $\mathbf{1 a}^{-}$and $\mathrm{K}$ [PhNNPh] can catalyse the dehydrocoupling of $\mathbf{1 a}$ to $\mathbf{2 a}$, inexpensive and commercially available $t \mathrm{BuOK}$ provides a convenient and practical entry point into the catalysis.

We also explored the reactivity of the hydrophosphination product $7 \mathbf{a}$ which was observed as a $P$-containing product along with 2a in reactions involving $10 \mathrm{~mol} \%$ of an alkali metal-based catalyst $\left(t \mathrm{BuOK}, \mathbf{1 a}^{-}\right.$, or $\left.\mathrm{K}[\mathrm{PhNNPh}]\right)$ and a $1: 1$ mixture of $\mathbf{1 a}$ and HA-2. Treatment of $7 \mathbf{a}$ with 1 equiv. of $t \mathrm{BuOK}$ or $\mathbf{1 a}^{-}$also resulted in conversion to $\mathbf{2 a}$, hydrazobenzene, and $\mathrm{K}[\mathrm{PhNNPh}]$ (Supplementary Fig. 21). In addition, treatment of a pure sample of independently synthesised $7 \mathrm{a}$ with $10 \mathrm{~mol} \% t \mathrm{BuOK}$ resulted in $\sim 43 \%$ conversion to $2 \mathbf{a}$ and hydrazobenzene and $\sim 7 \%$ conversion to 5 a within 5 min at $25^{\circ} \mathrm{C}$ (Supplementary Fig. 22). Similar product distributions were also obtained using either $10 \mathrm{~mol} \%$ $\mathbf{1 a}^{-}$or $\mathrm{K}[\mathrm{PhNNPh}]$ as catalysts (Supplementary Figs. 23 and 24). Interestingly the reaction of a 1:1 stoichiometric mixture of 1a and 7a with $10 \mathrm{~mol} \% t \mathrm{BuOK}$ or $\mathrm{K}[\mathrm{PhNNPh}]$ resulted in complete conversion to $\mathbf{2 a}$ and hydrazobenzene (Supplementary Figs. 25 and 26).

Radical trapping experiments with 1,4-cyclohexadiene, and experiments with added radical initiator di(t-butyl)peroxide (DTBP) were performed which are further supportive of a radical process (Supplementary Figs. 27 and 28). On the basis of the stoichiometric reactions and our key observation of the radical anion $\mathrm{K}[\mathrm{PhNNPh}]$ and the demonstrated competency of this species in catalysis we propose a radical mechanism initiated by one-electron reduction of $\mathbf{H A}-2$ to produce the radical anion $\mathrm{K}$ [PhNNPh] (Fig. 3c).

The oxidation potential for $t \mathrm{BuOK}$ is at $+0.10 \mathrm{~V}$ vs. SCE in DMF, ${ }^{51}$ meanwhile the reduction potential for azobenzene (HA2) is at $-1.36 \mathrm{~V}$ vs. SCE in DMF. ${ }^{73}$ Ashby and coworkers attempted to experimentally measure the oxidation potential of $\mathrm{K}$ $\left[\mathrm{PPh}_{2}\right]\left(\mathbf{1 a}^{-}\right)$in THF and were unsuccessful due to adsorption onto the Pt electrode, but concluded based on their studies on single electron transfer (SET) to organic iodides that they estimate the oxidation potential of $\mathbf{1 a}^{-}$to be in the range of +0.8 to $+1.3 \mathrm{~V}$ vs. SCE. ${ }^{74}$ It seems unlikely that $t \mathrm{BuOK}$ acts directly as the primary electron donor to azobenzene given that there is a significant mismatch of redox potentials and in our experiments only a small amount of radical was produced in the 1:1 reaction of HA-2 with $t \mathrm{BuOK}$. It is more likely that $\mathbf{1 a}^{-}$ generated under the catalytic conditions from the deprotonation reaction of $1 \mathrm{a}$ by $t \mathrm{BuOK}$ is engaged in electron transfer to HA-2 to initiate the radical chain process (Fig. 3c). In addition, the diphenylphosphide anion has been shown to participate in SET chemistry to a range of organic molecules either under photoirradiation, ${ }^{75,76}$ and without photoirradiation. ${ }^{74,77,78}$

It appears that in all reactions where an EPR signal was detectable that the only persistent radical species observed is the azobenzenyl radical anion $\mathrm{K}[\mathrm{PhNNPh}]$, this assignment is on the basis of the $g$-value and coupling constants, which matched closely with the literature values ${ }^{71,72}$ with varying degrees of spectral line broadening likely due to concentration and other solvent effects (see Supplementary Figs. 16-21 and 29). It is noteworthy that the $P$-based radical ${ }^{\circ} \mathrm{PPh}_{2}\left(\mathbf{l a}^{\prime}\right)$ does not persist under our reaction conditions since previously the EPR spectrum for this unstable intermediate was collected at $77 \mathrm{~K}, 79$ and therefore rapidly couples to give $\mathbf{2 a}$ (Fig. 3c).

It is noteworthy that the hydrophosphination adduct $7 \mathbf{a}$ can be converted both with and without a second equivalent of 1a upon the addition of either catalytic or stoichiometric quantities of 
$t \mathrm{BuOK}$ or $\mathbf{1} \mathbf{a}^{-}$. This gave a mixture of $\mathbf{2 a}$, hydrazobenzene, and $\mathrm{K}$ $[\mathrm{PhNNPh}]$. However, given that in the variable temperature NMR experiment (Supplementary Fig. 13) 7a was not observed until the sample was warmed to $25^{\circ} \mathrm{C}$ from $-60^{\circ} \mathrm{C}$, it is likely that $7 \mathbf{a}$ is an intermediate on a secondary pathway en route to $\mathbf{2 a}$ and not an essential or central intermediate on the primary pathway to 2a. This is in contrast to what was previously demonstrated using HA-5 where the resulting hydrophosphination adduct $\mathbf{3 a}$ was demonstrated to be a crucial intermediate.

A comparison between the use of $N$-benzylideneaniline (HA-5) and azobenzene (HA-2) was performed using different substituted phosphines (Fig. 4). For diphenylphosphine, although the yield of 2 a with HA-2 was lower than for the case of HA-5 (75\% vs $95 \%)$, it was achieved at milder temperature $\left(25^{\circ} \mathrm{C}\right.$ vs $\left.60^{\circ} \mathrm{C}\right)$ and with considerably shorter reaction time $(<5 \mathrm{~min}$ vs. $8 \mathrm{~h})$. From this point of view, HA-2 is still a practical hydrogen acceptor. Thus, additional phosphine substrates were explored: we found that in some cases HA-2 gave better conversion and yield of P-P coupled products than HA-5 (Fig. 4). For example, with fluoro- and chloro-substituted phosphines, more than $30 \%$ yield increases ( $78 \%$ vs. $46 \%$ and $87 \%$ vs. $55 \%$ ) were observed in each case at much lower temperature $\left(-20^{\circ} \mathrm{C} v s 130^{\circ} \mathrm{C}\right)$ and short reaction time ( $<5 \mathrm{~min}$ vs. $120 \mathrm{~h}$ ). For bis(mesityl)phosphine a $59 \%$ yield of diphosphine $\mathbf{2} \mathbf{h}$ was obtained using HA-2, while in the case of HA-5, no product was observed at all. The yield of $[\mathrm{PhP}]_{5}(\mathbf{2 i})$ was very high $(92 \%)$ for the dehydrocoupling of phenylphosphine. When cyclohexylphosphine was used as a substrate, $[\mathrm{CyP}]_{4}(2 \mathbf{j})$ was produced in $66 \%$ yield.

Heterodehydrocoupling of phosphines. Next, given the virtual absence of previous examples ${ }^{2}$, we investigated whether our $t \mathrm{BuOK}$-catalysed dehydrocoupling protocol could be extended to the heterodehydrocoupling of phosphines with different protic substrates $\left(\mathrm{R}^{3} \mathrm{E}-\mathrm{H}_{n} ; \mathrm{E}=\mathrm{N}, \mathrm{O}, \mathrm{S}, n=1,2\right)$. The initial reaction was

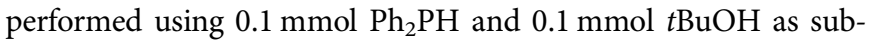
strates together with $0.1 \mathrm{mmol} \mathbf{H A}-5$ and $10 \mathrm{~mol} \% t \mathrm{BuOK}$ in $0.5 \mathrm{~mL}$ THF at $130^{\circ} \mathrm{C}$. We followed the reaction profile by ${ }^{31} \mathrm{P}$ NMR spectroscopy at different time intervals (Fig. 5a); the imine hydrophosphination adduct $\mathbf{3 a}$ is formed quantitatively after combining all the reagents. After heating the reaction mixture for $1 \mathrm{~h}$ we could observe both homodehydrocoupling product $\mathbf{2 a}$ and heterodehydrocoupling product $5 \mathbf{a}$. Both $\mathbf{2 a}$ and $\mathbf{5 a}$ were present during the reaction and eventually all $\mathbf{2 a}$ was converted to give $5 \mathbf{a}$ in $90 \%$ yield together with some other minor side products. Computationally the heterodehydrocoupling reaction of 1a with $t \mathrm{BuOH}$ in the presence of $\mathbf{H A}-\mathbf{5}$ to produce $5 \mathbf{a}$ and 4a was exergonic by $10.62 \mathrm{kcal} \mathrm{mol}^{-1}$, similar to the computed value of $\Delta G=-10.09 \mathrm{kcal} \mathrm{mol}^{-1}$ for the analogous homodehydrocoupling process (see Supplementary Discussion in the Supplementary Information and Supplementary Data 1 and 2). The similarly favourable thermodynamics calculated for the $\mathrm{P}-\mathrm{P}$ and $\mathrm{P}-\mathrm{O}$ coupling reactions suggest that both reactions are possible, and likely competitive. The further conversion of $\mathbf{2 a}$ to $\mathbf{5 a}$ in the presence of additional $t \mathrm{BuOH}$ allows for high yield of $\mathbf{5 a}$.

We then performed the heterodehydrocoupling reactions of secondary and primary phosphines with alcohols, amines or thiols in the presence of either azobenzene (HA-2) or imine (HA5). As shown in Fig. 5b, we observed that HA-2 was able to mediate the heterodehydrocoupling of diphenylphosphine with either $t \mathrm{BuOH}$ or aniline at $25^{\circ} \mathrm{C}$ with very high yields $(93 \%$ and $87 \%$, respectively). At $25^{\circ} \mathrm{C}$ with $p$-thiocresol there was no reaction; however, after heating at $130{ }^{\circ} \mathrm{C}$ for only $3 \mathrm{~h}$, the heterodehydrocoupling product $\mathbf{8 a}$ was obtained in $90 \%$ yield. Using HA-5 on the other hand, all reactions involving diphenylphosphine required heating at $130^{\circ} \mathrm{C}$ to obtain excellent
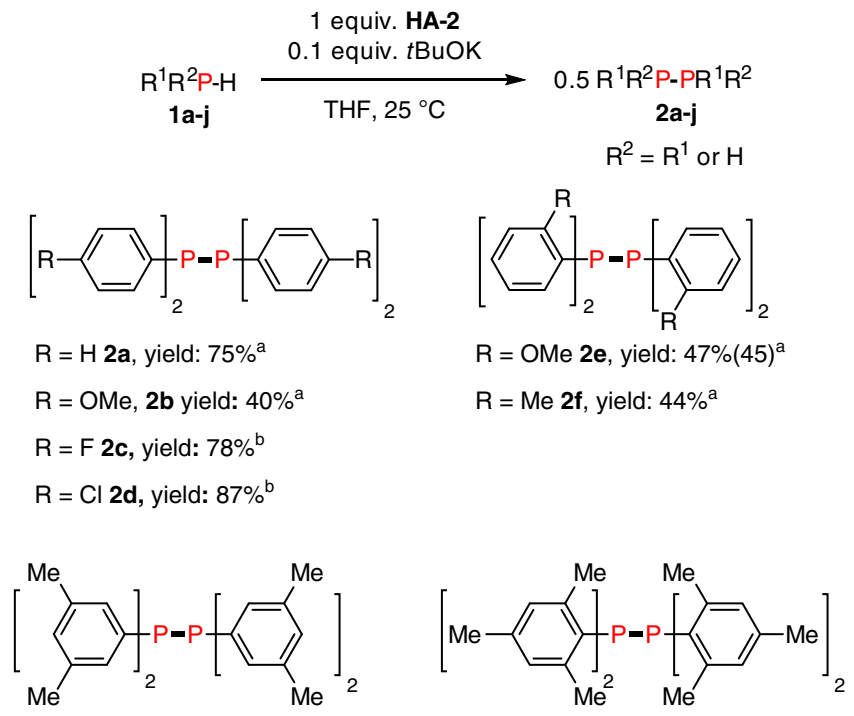

2 g yield: $72 \%{ }^{a}$

2h yield: $59 \%(55)^{\mathrm{c}}$

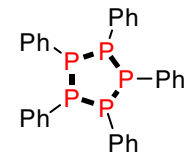

2i yield: $92 \%^{\mathrm{a}}$

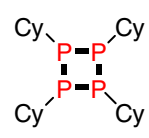

2j yield: $66 \%(60)^{\mathrm{c}}$
Fig. 4 Reaction generality for the dehydrocoupling of different phosphines with $\mathrm{HA}-2$ : reactions were performed with $0.1 \mathrm{mmol}$ phosphines, $0.01 \mathrm{mmol}$ tBuOK, $0.1 \mathrm{mmol}$ HA-2, $0.5 \mathrm{~mL}$ THF in a J. Young NMR tube and yields were based on the phosphine as the limiting reagent and determined by ${ }^{31} \mathrm{P}$ $\left\{{ }^{1} \mathrm{H}\right\}$ NMR spectroscopy using a capillary of $\mathrm{PCl}_{3}$ as a calibration standard, the numbers in brackets were isolated yields. ${ }^{a} 25^{\circ} \mathrm{C}$ within $5 \mathrm{~min}, \mathrm{~b}_{-}-20^{\circ} \mathrm{C}$ within $5 \mathrm{~min},{ }^{\mathrm{c}} 130^{\circ} \mathrm{C}$ for $1 \mathrm{~h}$

yields (90\% and $85 \%$ ) except for the case of reaction with aniline where only a moderate yield of $\mathbf{6 a}$ (54\%) was observed. When phenylphosphine was used as the substrate with HA-2 the heterodehydrocoupling with $t \mathrm{BuOH}$ produced only $8 \%$ of the doubly-dehydrocoupled product $\mathbf{9} \mathbf{a}^{\prime}$, while with HA-5 the yields were $48 \%$ for singly-dehydrocoupled product $9 \mathbf{a}$ and $20 \%$ for $\mathbf{9} \mathbf{a}^{\prime}$. When phenylphosphine was reacted with aniline in the presence of HA-2 we also observed the formation of only doubly dehydrocoupled $\mathbf{1 0 a ^ { \prime }}$ in $47 \%$ yield and with HA-5 a $34 \%$ yield of $10 \mathbf{a}^{\prime}$ was obtained. The reaction with $p$-thiocresol mediated by HA-2 produced $87 \%$ doubly-dehydrocoupled product $11 \mathbf{a}^{\prime}$ alongside only $8 \%$ of $11 \mathrm{a}$, while the use of HA-5 led to the formation of $44 \% \mathbf{1 1} \mathbf{a}^{\prime}$ and $29 \%$ of $\mathbf{1 1 a}$.

Dehydrocoupling of phosphines with hydrazobenzene. During our studies of the dehydrocoupling mechanism using HA-2 we were surprised to discover that in the presence of hydrogenation product from HA-2, hydrazobenzene, with $\mathrm{Ph}_{2} \mathrm{PH}$ (1a), the homodehydrocoupling product 2 a could also be observed (Fig. 6). We therefore determined whether it was possible to use hydrazobenzene as an HA directly. The reaction with $0.1 \mathrm{mmol} \mathbf{1 a}$ and $0.1 \mathrm{mmol}$ hydrazobenzene and $0.5 \mathrm{~mL}$ THF in a J. Young NMR tube was monitored using ${ }^{31} \mathrm{P}$ NMR spectroscopy (Fig. 6a). It is noteworthy that the formation of $2 \mathbf{a}$ took place readily at $25^{\circ} \mathrm{C}$. However, a stoichiometric amount of $t \mathrm{BuOK}$ was required for a full conversion as the gradual addition of $t \mathrm{BuOK}$ to $0.1 \mathrm{mmol}$ increased the yield of $\mathbf{2 a}$ to $93 \%$. 
a

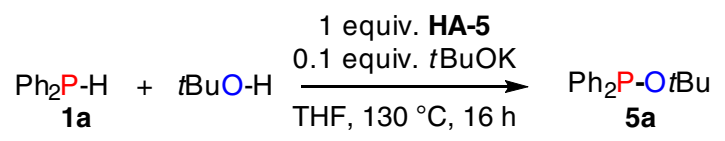

yield: $90 \%$

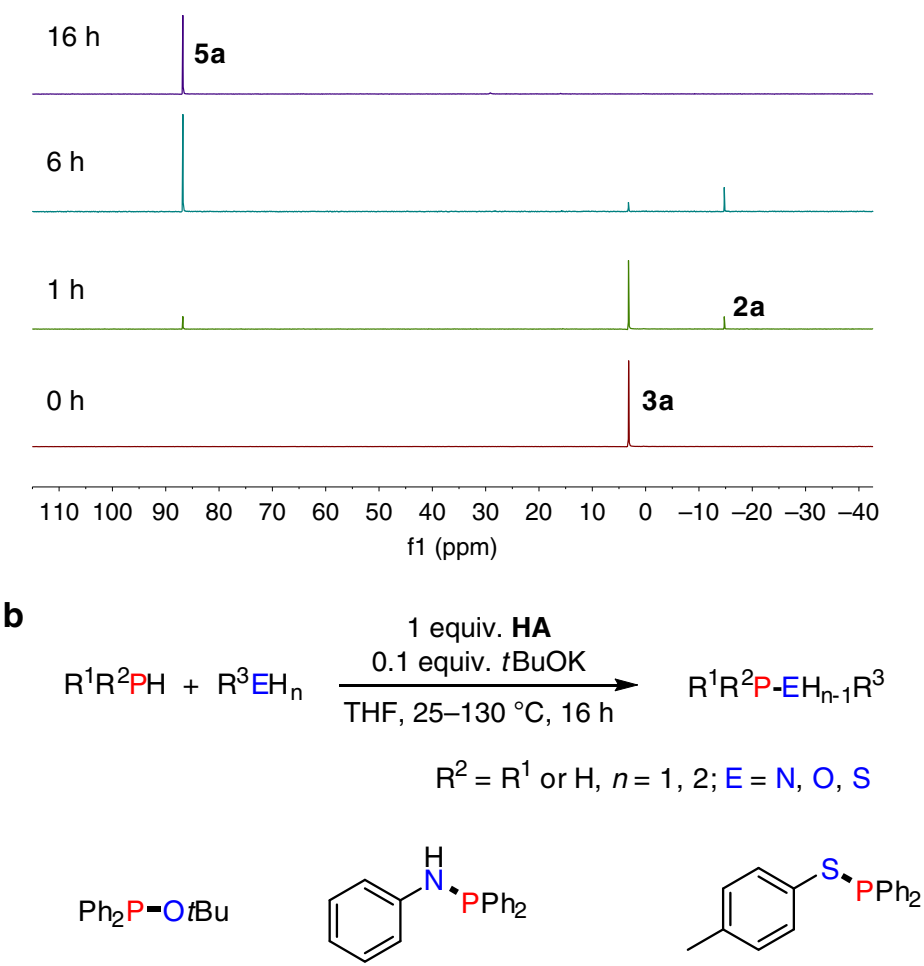

5a HA-2 yield: $93 \%(88)^{a} \quad$ 6a HA-2 yield: $87 \%(80)^{a}$

HA-5 yield: $90 \%{ }^{b}$<smiles>CCCCCOP</smiles><smiles>CCOC(C)(CC)P(C)(C)(Br)c1ccccc1</smiles>

HA-2 ${ }^{a}$ 9a $0 \%, 9 a^{\prime} 8 \%$

HA-5 ${ }^{b}$ 9a $48 \%$, 9a' $20 \%$
HA-5 yield: $54 \%{ }^{b}$<smiles>c1ccc(NPc2ccccc2)cc1</smiles><smiles>CP(c1ccccc1)C(C)(Nc1ccccc1)c1ccccc1</smiles>

HA-2 $^{b}$ 10a 0\%,10a' 47\% (44)

HA $-5^{b} 10$ a $0 \%, 10 a^{\prime} 34 \%$ 8a HA-2 yield: $90 \%(85)^{b}$

HA-5 yield: $85 \%$<smiles>Cc1ccc(SPc2ccccc2)cc1</smiles>

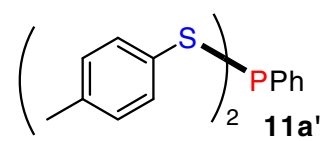

$\mathrm{HA}^{b}{ }^{b} 11 \mathrm{a} 8 \%, 11 \mathrm{a}^{\prime} 87 \%$

Fig. 5 Heterodehydrocoupling of phosphines. a ${ }^{31} \mathrm{P}\left\{{ }^{1} \mathrm{H}\right\}$ NMR spectra of $t \mathrm{BuOK}$-catalysed heterodehydrocoupling of $\mathbf{1 a}$ with $t \mathrm{BuOH}$ in THF. $\mathbf{b}$ Reaction generality of catalytic heterodehydrocoupling of phosphines with alcohol, amine and thiol: reactions were performed with $0.1 \mathrm{mmol}$ phosphines, 0.1-0.3 mmol of R ${ }^{3} E-H_{n} ; E=N, O, S, n=1,2$ and 0.01 mmol tBuOK, 0.1 mmol HA-5 or HA-2, $0.5 \mathrm{~mL}$ THF in a J. Young NMR tube and yields were based on the phosphine as the limiting reagent and were determined by ${ }^{31} \mathrm{P}\left\{{ }^{1} \mathrm{H}\right\} \mathrm{NMR}$ spectroscopy using a capillary of $\mathrm{PCl}_{3}$ as a calibration standard, the numbers in brackets were isolated yields. ${ }^{\mathrm{a}} 25^{\circ} \mathrm{C}, \mathrm{b} 130^{\circ} \mathrm{C}$

The 1:1 stoichiometric reaction of hydrazobenzene with either $t \mathrm{BuOK}$ or $\mathrm{K}\left[\mathrm{PPh}_{2}\right]$ in $\mathrm{THF}$ at $25^{\circ} \mathrm{C}$ resulted in immediate formation of a brown reaction mixture which displayed the diagnostic signal in the EPR spectrum corresponding to the $\mathrm{K}$ [PhNNPh], analogous to reactions where HA-2 was used (Supplementary Fig. 29). Examples of the dehydrogenation reaction of hydrazobenzenes to azobenzenes mediated by $t \mathrm{BuOK}$ and other alkali metal compounds are known in the literature ${ }^{80,81}$. It therefore seems likely that in situ generation of
HA-2 and subsequent radical species are involved in the dehydrocoupling of phosphines involving hydrazobenzene and a stoichiometric amount of $t \mathrm{BuOK}$.

Subsequently, the generality of using hydrazobenzene in the homodehydrocoupling of phosphines was studied (Fig. 6b). We found that improved yields were obtained compared to the use of HA-2 or HA-5 and all reactions were completed within $5 \mathrm{~min}$. Our system was tolerant to various functional groups, thus phosphines with methoxy- and methyl- and $N$, 
a

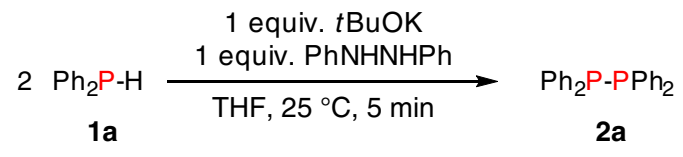

1.0 equiv. $t \mathrm{BuOK}$

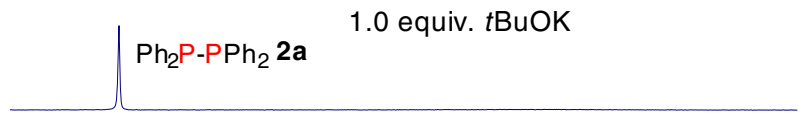

0.5 equiv. $t \mathrm{BuOK}$

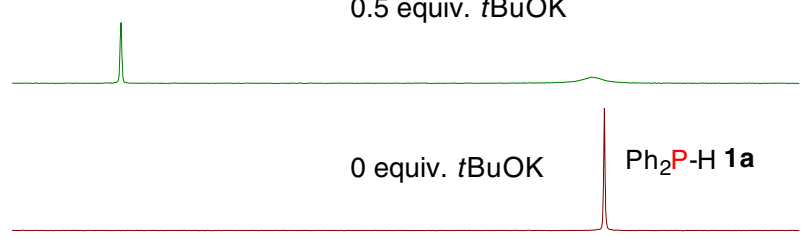

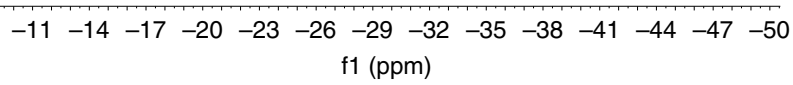

b

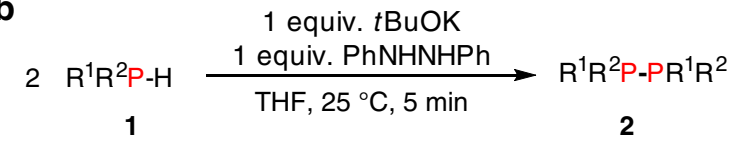<smiles>CPc1ccc(P(C)P(C)c2ccc(PC)cc2)cc1</smiles>

$\mathrm{R}=\mathrm{H} \mathbf{2 a}$, yield: $93 \%$

$\mathrm{R}=\mathrm{OMe}, \mathbf{2} \mathrm{b}$ yield: $86 \%$

$\mathrm{R}=$ Me 2k, yield: $91 \%^{\mathrm{b}}$

$\mathrm{R}=\mathrm{NMe}_{2} 2 \mathrm{I}$, yield: $93 \%(81)^{\mathrm{b}}$

Fig. 6 Catalytic homodehydrocoupling of phosphines using hydrazobenzene as $\mathrm{HA}$. a ${ }^{31} \mathrm{P}\left\{{ }^{1} \mathrm{H}\right\}$ NMR spectra in THF with different amounts of added tBuOK for the dehydrocoupling of $\mathbf{1 a}$ in the presence of hydrazobenzene. b Catalytic results with different substituted phosphines: reactions were performed with $0.1 \mathrm{mmol}$ phosphines, $0.1 \mathrm{mmol}$ tBuOK and $0.1 \mathrm{mmol}$ hydrazobenzene, $0.5 \mathrm{~mL}$ THF at $25^{\circ} \mathrm{C}$ in a J. Young NMR tube and yields were based on the phosphine as the limiting reagent and determined by ${ }^{31} \mathrm{P}$ $\left\{{ }^{1} \mathrm{H}\right\}$ NMR spectroscopy using a capillary of $\mathrm{PCl}_{3}$ as a calibration standard, the number in brackets shows an isolated yield

$N$-dimethyl-substituents at para and ortho- positions all reacted well and gave the homodehydrocoupling products $(\mathbf{2 a - b}, \mathbf{2 e - f}$, $\mathbf{2 k - 1 )}$ in very high yields (71-93\%).

After establishing the hydrazobenzene-mediated homodehydrocoupling of phosphines, we then explored the possible extension to heterodehydrocoupling processes (Fig. 7). In general, we found that the reaction was successful, albeit with moderate product yields. For example, in the presence of 1 equiv. hydrazobenzene, diphenylphosphine reacted with aniline and produced $\mathbf{6 a}$ in $52 \%$ yield. For primary phenylphosphine, doublydehydrocoupled products $\mathbf{9} \mathbf{a}^{\prime}$ and $\mathbf{1 1} \mathbf{a}^{\prime}$ were formed with $t \mathrm{BuOH}$ and $p$-thiocresol in moderate to good yield (45\% and 59\%, respectively).

\section{Discussion}

We have demonstrated that cheap and commercially available $t \mathrm{BuOK}$ was capable of catalysing the homodehydrocoupling of phosphines $\left(\mathrm{R}^{1} \mathrm{R}^{2} \mathrm{PH}, \mathrm{R}^{2}=\mathrm{R}^{1}\right.$ or $\left.\mathrm{H}\right)$ in the presence of hydrogen

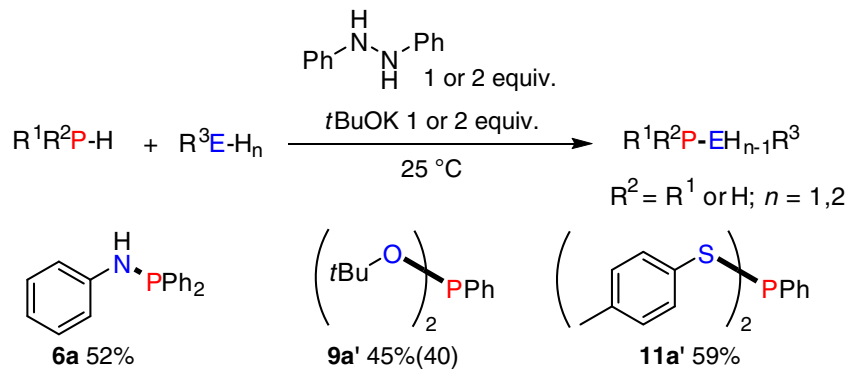

Fig. 7 Hydrazobenzene-mediated heterodehydrocoupling of phosphines with alcohols, thiols, and amines: reactions were performed with $0.1 \mathrm{mmol}$ phosphines, $0.1-0.2 \mathrm{mmol} t \mathrm{BuOK}$ and $0.1-0.2 \mathrm{mmol}$ hydrazobenzene in $0.5 \mathrm{~mL} \mathrm{THF}$ at $25^{\circ} \mathrm{C}$ for $8 \mathrm{~h}$ in a J. Young NMR tube and yields were based on the phosphine as the limiting reagent and were determined by ${ }^{31} \mathrm{P}\left\{{ }^{1} \mathrm{H}\right\}$ NMR spectroscopy using a capillary of $\mathrm{PCl}_{3}$ as a calibration standard, the number in brackets shows an isolated yield

acceptors such as an imine or azobenzene to produce molecules containing $\mathrm{P}-\mathrm{P}$ bonds. Milder reaction conditions $\left(25^{\circ} \mathrm{C}\right)$ and fast reaction times $(<5 \mathrm{~min})$ allow this process to be more practical and general for a variety of different substituted diphosphines. This is in contrast to the previously reported processes which generally use expensive transition metal catalysts or reagents requiring multi-step syntheses, harsh reaction conditions, and substantially longer reaction times. We found that imines and azobenzene play an intimate mechanistic role in facilitating the dehydrocoupling reactions rather than simply functioning as $\mathrm{H}_{2}$-acceptors. It appears that two different reaction mechanisms operate: for imines an ionic mechanism involving a hydrophosphination adduct as a key intermediate was elucidated whereas for azobenzene, evidence for an alternative, radical coupling mechanism was apparent. In addition, saturated hydrazobenzene was also able to mediate the homodehydrocoupling reactions involving phosphines with stoichiometric amount of $t \mathrm{BuOK}$ and superior yields of the dehydrocoupled products are obtained compared to azobenzene. Significantly, a general procedure for the heterodehydrocoupling of phosphines with various main group substrates $\left(\mathrm{R}^{3} \mathrm{EH}_{\mathrm{n}}, \mathrm{E}=\mathrm{O}\right.$, $\mathrm{S}, \mathrm{N}, n=1$ or 2 ) was also established and this provides a convenient route to compounds containing $\mathrm{P}-\mathrm{O}, \mathrm{P}-\mathrm{S}$, or $\mathrm{P}-\mathrm{N}$ bonds. This chemistry may prove useful in the future for the preparation of phosphorus compounds with applications in biological and agrochemistry as well as in catalysis. Our current work focuses on further expansion of the substrate scope and additional detailed mechanistic studies.

\section{Methods}

tBuOK-catalysed homodehydrocoupling of phosphines. A J. Young NMR tube was charged with $0.1 \mathrm{mmol}$ of the phosphines and $0.1 \mathrm{mmol}$ of the corresponding hydrogen acceptors azobenzene (HA-2) or $N$-benzylideneaniline (HA-5), $0.5 \mathrm{~mL}$ of $0.02 \mathrm{M} t \mathrm{BuOK}$ THF solution was added to the J. Young NMR tube. The NMR tube was sealed and heated at various temperature as indicated in the corresponding Fig. 2 and Fig. 4 or Supplementary Tables 1-6 for the time shown and analysed by ${ }^{31} \mathrm{P}$ NMR spectroscopy. For isolated products, the solvents/volatiles were removed under vacuum and the residue was washed with hexanes, solid products were recrystallised through vapour diffusion of hexanes into THF solutions of the product.

tBuOK-catalysed heterodehydrocoupling of phosphines. A J. Young NMR tube was charged with $0.1 \mathrm{mmol}$ of the phosphines and $0.1 \mathrm{mmol}$ of azobenzene (HA-2) or $N$-benzylideneaniline (HA-5), $0.5 \mathrm{~mL}$ of $0.02 \mathrm{M} t \mathrm{BuOK}$ THF solution was added to the J. Young NMR tube, then $0.1-0.3 \mathrm{mmol}$ of the corresponding alcohol, thiol, or amine was added. The NMR tube was sealed and heated for the time shown in the Fig. 5 and analysed by ${ }^{31} \mathrm{P}$ NMR spectroscopy. For isolated products, the reactions were performed in $0.5 \mathrm{mmol}$ scale of phosphine and distilled under lower pressure for liquid products or purified via diffusion crystallisation (THF/hexane). 
Homodehydrocoupling of phosphines using hydrazobenzene. A J. Young NMR tube was charged with $0.1 \mathrm{mmol}$ of the phosphines and $0.1 \mathrm{mmol}$ hydrazobenzene, $0.5 \mathrm{~mL}$ of $0.2 \mathrm{M} t \mathrm{BuOK}$ THF solution was added to the J. Young NMR tube. The NMR tube was sealed and analysed directly by ${ }^{31} \mathrm{P}$ NMR spectroscopy. The isolated products were obtained via diffusion crystallisation (THF/hexane).

\section{Data availability}

All data to support the conclusions in this paper are available in the main text or the supplementary materials. Crystallographic data for $\mathbf{2 j}$ (CCDC 1842531) and 3e.(THF) (CCDC 1842532) are available from the Cambridge Crystallographic Data Centre. Copies of the data can be obtained free of charge from [www.ccdc.cam.ac.uk/data_request/cif].

Received: 17 June 2018 Accepted: 21 March 2019

Published online: 26 June 2019

\section{References}

1. Gauvin, F., Harrod, J. F. \& Woo, H. G. in Adv. Organomet. Chem. Vol. 42 (eds Gordon, F., Stone A. \& Robert, West) 363-405 (Academic Press, Cambridge, 1998).

2. Han, L.-B. \& Tilley, T. D. Selective homo- and heterodehydrocouplings of phosphines catalyzed by rhodium phosphido complexes. J. Am. Chem. Soc. 128, 13698-13699 (2006).

3. Waterman, R. Dehydrogenative bond-forming catalysis involving phosphines. Curr. Org. Chem. 12, 1322-1339 (2008).

4. Less, R. J., Melen, R. L., Naseri, V. \& Wright, D. S. Recent perspectives on main group-mediated dehydrocoupling of P-P bonds. Chem. Commun. 4929-4937 (2009).

5. Leitao, E. M., Jurca, T. \& Manners, I. Catalysis in service of main group chemistry offers a versatile approach to $p$-block molecules and materials. Nat. Chem. 5, 817-829 (2013).

6. Melen, R. L. Dehydrocoupling routes to element-element bonds catalysed by main group compounds. Chem. Soc. Rev. 45, 775-788 (2016)

7. Greenberg, S. \& Stephan, D. W. Stoichiometric and catalytic activation of P-H and P-P bonds. Chem. Soc. Rev. 37, 1482-1489 (2008).

8. Dorn, H. et al. Transition metal-catalyzed formation of phosphorus-boron bonds: a new route to phosphinoborane rings, chains, and macromolecules. $J$. Am. Chem. Soc. 122, 6669-6678 (2000).

9. Johnson, H. C. et al. Mechanistic studies of the dehydrocoupling and dehydropolymerization of amine-boranes using a $[\mathrm{Rh}(\text { Xantphos })]^{+}$catalyst. $J$. Am. Chem. Soc. 136, 9078-9093 (2014).

10. Choffat, F. et al. Synthesis and characterization of linear poly(dialkylstannane)s. Macromolecules 40, 7878-7889 (2007).

11. Sloan, M. E., Clark, T. J. \& Manners, I. Homogeneous catalytic dehydrogenation/dehydrocoupling of amine-borane adducts by the $\mathrm{Rh}(\mathrm{I})$ Wilkinson's complex analogue $\mathrm{RhCl}\left(\mathrm{PHCy}_{2}\right)_{3}(\mathrm{Cy}=$ cyclohexyl). Inorg. Chem. 48, 2429-2435 (2009).

12. Paul, U. S. D., Braunschweig, H. \& Radius, U. Iridium-catalysed dehydrocoupling of aryl phosphine-borane adducts: synthesis and characterisation of high molecular weight poly(phosphinoboranes). Chem Commun. 52, 8573-8576 (2016).

13. Kumar, A. et al. Multiple metal-bound oligomers from Ir-catalysed dehydropolymerisation of $\mathrm{H}_{3} \mathrm{~B} \cdot \mathrm{NH}_{3}$ as probed by experiment and computation. Chem. Sci. 5, 2546-2553 (2014).

14. Staubitz, A. et al. Catalytic dehydrocoupling/dehydrogenation of Nmethylamine-borane and ammonia-borane: synthesis and characterization of high molecular weight polyaminoboranes. J. Am. Chem. Soc. 132, 13332-13345 (2010).

15. Denney, M. C., Pons, V., Hebden, T. J., Heinekey, D. M. \& Goldberg, K. I. Efficient catalysis of ammonia borane dehydrogenation. J. Am. Chem. Soc. 128, 12048-12049 (2006).

16. Marziale, A. N. et al. The mechanism of borane-amine dehydrocoupling with bifunctional ruthenium catalysts. J. Am. Chem. Soc. 135, 13342-13355 (2013).

17. Sun, C.-L. \& Shi, Z.-J. Transition-metal-free coupling reactions. Chem. Rev. 114, 9219-9280 (2014).

18. Rossin, A. \& Peruzzini, M. Ammonia-borane and amine-borane dehydrogenation mediated by complex metal hydrides. Chem. Rev. 116, 8848-8872 (2016).

19. Han, D., Anke, F., Trose, M. \& Beweries, T. Recent advances in transition metal catalysed dehydropolymerisation of amine boranes and phosphine boranes. Coord. Chem. Rev. 380, 260-286 (2019).

20. Imori, T., Lu, V., Cai, H. \& Tilley, T. D. Metal-catalyzed dehydropolymerization of secondary stannanes to high molecular weight polystannanes. J. Am. Chem. Soc. 117, 9931-9940 (1995).
21. Metters, O. J. et al. Catalytic dehydrocoupling of amine-boranes using cationic zirconium(IV)-phosphine frustrated lewis pairs. ACS Catal. 6, 6601-6611 (2016).

22. Roering, A. J., MacMillan, S. N., Tanski, J. M. \& Waterman, R. Zirconiumcatalyzed heterodehydrocoupling of primary phosphines with silanes and germanes. Inorg. Chem. 46, 6855-6857 (2007).

23. Baker, R. T. et al. Iron complex-catalyzed ammonia-borane dehydrogenation. A potential route toward $\mathrm{B}-\mathrm{N}$-containing polymer motifs using earthabundant metal catalysts. J. Am. Chem. Soc. 134, 5598-5609 (2012).

24. Vance, J. R. et al. Iron-catalyzed dehydrocoupling/dehydrogenation of amine-boranes. J. Am. Chem. Soc. 136, 3048-3064 (2014).

25. Keaton, R. J., Blacquiere, J. M. \& Baker, R. T. Base metal catalyzed dehydrogenation of ammonia-borane for chemical hydrogen storage. J. Am. Chem. Soc. 129, 1844-1845 (2007).

26. Vogt, M., de Bruin, B., Berke, H., Trincado, M. \& Grützmacher, H. Amino olefin nickel(I) and nickel(0) complexes as dehydrogenation catalysts for amine boranes. Chem. Sci. 2, 723-727 (2011).

27. Liptrot, D. J., Hill, M. S., Mahon, M. F. \& MacDougall, D. J. Group 2 promoted hydrogen release from $\mathrm{NMe}_{2} \mathrm{H} \cdot \mathrm{BH}_{3}$ : intermediates and catalysis Chem. Eur. J. 16, 8508-8515 (2010)

28. Cowley, H. J., Holt, M. S., Melen, R. L., Rawson, J. M. \& Wright, D. S. Catalytic dehydrocoupling of $\mathrm{Me}_{2} \mathrm{NHBH}_{3}$ with $\mathrm{Al}\left(\mathrm{NMe}_{2}\right)_{3}$. Chem. Commun. 47, 2682-2684 (2011).

29. Wu, L., Chitnis, S. S., Jiao, H., Annibale, V. T. \& Manners, I. Non-metalcatalyzed heterodehydrocoupling of phosphines and hydrosilanes: mechanistic studies of $\mathrm{B}\left(\mathrm{C}_{6} \mathrm{~F}_{5}\right)_{3}$-mediated formation of P-Si bonds. J. Am. Chem. Soc. 139, 16780-16790 (2017)

30. Bellham, P., Hill, M. S. \& Kociok-Köhn, G. Alkali metal-mediated dehydrocoupling of $\mathrm{Me}_{2} \mathrm{NH} \cdot \mathrm{BH}_{3}$. Dalton Trans. 44, 12078-12081 (2015).

31. McLellan, R., Kennedy, A. R., Mulvey, R. E., Orr, S. A. \& Robertson, S. D. 1Alkali-metal-2-alkyl-1,2-dihydropyridines: soluble hydride surrogates for catalytic dehydrogenative coupling and hydroboration applications. Chem. Eur. J. 23, 16853-16861 (2017)

32. Nolla-Saltiel, R., Geer, A. M., Lewis, W., Blake, A. J. \& Kays, D. L. Dehydrogenation of dimethylamine-borane mediated by Group I pincer complexes. Chem. Commun. 54, 1825-1828 (2018).

33. Molitor, S., Mahler, C. \& Gessner, V. H. Synthesis and solid-state structures of gold(I) complexes of diphosphines. New J. Chem. 40, 6467-6474 (2016).

34. Geier, S. J. \& Stephan, D. W. Activation of $\mathrm{P}_{5} \mathrm{R}_{5}(\mathrm{R}=\mathrm{Ph}, \mathrm{Et})$ by a Rh- $\beta-$ diketiminate complex. Chem. Commun. 2779-2781 (2008).

35. Annibale, V. T., Ostapowicz, T. G., Westhues, S., Wambach, T. C. \& Fryzuk, M. D. Synthesis of a sterically bulky diphosphine synthon and $\mathrm{Ru}(\mathrm{II})$ complexes of a cooperative tridentate enamide-diphosphine ligand platform. Dalton Trans. 45, 16011-16025 (2016).

36. Chitnis, S. S. et al. Addition of a cyclophosphine to nitriles: an inorganic click reaction featuring protio, organo, and main-group catalysis. Angew. Chem. Int. Ed. 56, 9536-9540 (2017).

37. Feldmann, K.-O. \& Weigand, J. J. P-N/P-P bond metathesis for the synthesis of complex polyphosphanes. J. Am. Chem. Soc. 134, 15443-15456 (2012).

38. Hirano, K. \& Miura, M. Recent advances in diphosphination of alkynes and alkenes. Tetrahedron Lett. 58, 4317-4322 (2017).

39. Hajdók, I., Lissner, F., Nieger, M., Strobel, S. \& Gudat, D. Diphosphination of electron poor alkenes. Organometallics 28, 1644-1651 (2009).

40. Sato, Y., Kawaguchi, S.-i, Nomoto, A. \& Ogawa, A. Highly selective phosphinylphosphination of alkenes with tetraphenyldiphosphine monoxide. Angew. Chem. Int. Ed. 55, 9700-9703 (2016).

41. Fermin, M. C. \& Stephan, D. W. Catalytic oligomerization of primary phosphines by the anionic zirconocene trihydride: $\left[\mathrm{Cp}^{*}{ }_{2} \mathrm{ZrH}_{3}\right]^{-}$. J. Am. Chem. Soc. 117, 12645-12646 (1995).

42. Böhm, V. P. W. \& Brookhart, M. Dehydrocoupling of phosphanes catalyzed by a rhodium(I) complex. Angew. Chem. Int. Ed. 40, 4694-4696 (2001).

43. Waterman, R. Selective dehydrocoupling of phosphines by triamidoamine zirconium catalysts. Organometallics 26, 2492-2494 (2007).

44. King, A. K., Buchard, A., Mahon, M. F. \& Webster, R. L. Facile, catalytic dehydrocoupling of phosphines using $\beta$-diketiminate iron(II) complexes. Chem. Eur. J. 21, 15960-15963 (2015).

45. Naseri, V., Less, R. J., Mulvey, R. E., McPartlin, M. \& Wright, D. S. Stoichiometric and catalytic Sn-mediated dehydrocoupling of primary phosphines. Chem. Commun. 46, 5000-5002 (2010).

46. Dobrovetsky, R., Takeuchi, K. \& Stephan, D. W. Metal-free Lewis acid mediated dehydrocoupling of phosphines and concurrent hydrogenation. Chem. Commun. 51, 2396-2398 (2015).

47. Molitor, S., Becker, J. \& Gessner, V. H. Selective dehydrocoupling of phosphines by lithium chloride carbenoids. J. Am. Chem. Soc. 136 15517-15520 (2014)

48. Schneider, H., Schmidt, D. \& Radius, U. The reductive P-P coupling of primary and secondary phosphines mediated by N-heterocyclic carbenes. Chem. Commun. 51, 10138-10141 (2015). 
49. Ashford, R. D. Ashford's Dictionary of Industrial Chemicals: Properties, Production, Uses. (Wavelength, London, 1994).

50. Murphy, P. J. Organophosphorus Reagents. (Oxford University Press, Oxford, 2004).

51. Barham, J. P. et al. KOtBu: a privileged reagent for electron transfer reactions? J. Am. Chem. Soc. 138, 7402-7410 (2016).

52. Kumar, A. et al. C-C bond formation of benzyl alcohols and alkynes using a catalytic amount of $\mathrm{KO}^{\mathrm{t}} \mathrm{Bu}$ : Unusual regioselectivity through a radical mechanism. Angew. Chem. Int. Ed. 58, 3373-3377 (2019).

53. Liu, W. B. et al. Potassium tert-butoxide-catalyzed dehydrogenative C-H silylation of heteroaromatics: a combined experimental and computational mechanistic study. J. Am. Chem. Soc. 139, 6867-6879 (2017).

54. Weickgenannt, A. \& Oestreich, M. Potassium tert-butoxide-catalyzed dehydrogenative Si-O coupling: reactivity pattern and mechanism of an underappreciated alcohol protection. Chem. Asian J. 4, 406-410 (2009).

55. Evoniuk, C. J. et al. Coupling $\mathrm{N}-\mathrm{H}$ deprotonation, $\mathrm{C}-\mathrm{H}$ activation, and oxidation: metal-free $\mathrm{C}\left(\mathrm{sp}^{3}\right)-\mathrm{H}$ aminations with unprotected anilines. J. Am. Chem. Soc. 139, 16210-16221 (2017).

56. Yin, Q., Klare, H. F. \& Oestreich, M. Catalytic Friedel-Crafts C-H borylation of electron-rich arenes: dramatic rate acceleration by added alkenes. Angew. Chem. Int. Ed. 56, 3712-3717 (2017)

57. Pérez, M., Caputo, C. B., Dobrovetsky, R. \& Stephan, D. W. Metal-free transfer hydrogenation of olefins via dehydrocoupling catalysis. Proc. Natl Acad. Sci. 111, 10917-10921 (2014).

58. Bunlaksananusorn, T. \& Knochel, P. $t$-BuOK-catalyzed addition phosphines to functionalized alkenes: a convenient synthesis of polyfunctional phosphine derivatives. Tetrahedron Lett. 43, 5817-5819 (2002).

59. King, R. B., Cloyd, J. C. \& Kapoor, P. N. Syntheses and properties of novel polyphosphines containing various combinations of primary, secondary, and tertiary phosphorus atoms. J. Chem. Soc. Perkin Trans. 1, 2226-2229 (1973).

60. Yoshimura, A. et al. An efficient base-catalyzed double addition of $\mathrm{H}-$ phosphine oxides to alkynes. Tetrahedron Lett. 57, 3382-3384 (2016).

61. Andrieu, J., Dietz, J., Poli, R. \& Richard, P. Reversible P-C bond formation for saturated $\alpha$-aminophosphine ligands in solution: stabilization by coordination to $\mathrm{Cu}(\mathrm{I})$. New J. Chem. 23, 581-583 (1999).

62. van Bochove, M. A., Swart, M. \& Bickelhaupt, F. M. Nucleophilic substitution at phosphorus $\left(\mathrm{S}_{\mathrm{N}} 2 @ \mathrm{P}\right)$ : disappearance and reappearance of reaction barriers. J. Am. Chem. Soc. 128, 10738-10744 (2006).

63. León, T., Riera, A. \& Verdaguer, X. Stereoselective synthesis of P-stereogenic aminophosphines: ring opening of bulky oxazaphospholidines. J. Am. Chem. Soc. 133, 5740-5743 (2011).

64. Kolodiazhnyi, O. I. \& Kolodiazhna, A. Nucleophilic substitution at phosphorus: stereochemistry and mechanisms. Tetrahedron: Asymmetry. 28, 1651-1674 (2017).

65. Brook, A. G. \& Duff, J. M. Base-catalyzed rearrangement of aminomethylsilanes to methylaminosilanes. J. Am. Chem. Soc. 96, 4692-4693 (1974).

66. Duff, J. M. \& Brook, A. G. Studies of the rearrangements of aminoalkylsilanes to alkylaminosilanes. Can. J. Chem. 55, 2589-2600 (1977).

67. Capozzi, M. A. M., Cardellicchio, C. \& Naso, F. Enantioselective routes to sulfoxides based upon the use of carbanionic leaving groups. Eur. J. Org. Chem. 1855-1963 (2004)

68. Lin, S. et al. An expedient synthesis of carbazoles through potassium tertbutoxide-promoted intramolecular direct $\mathrm{C}-\mathrm{H}$ bond arylation. Eur. J. Org. Chem. 2017, 443-447 (2017).

69. Liu, W. \& Hou, F. Transition-metal-free dehalogenation of aryl halides promoted by phenanthroline/potassium tert-butoxide. Tetrahedron 73, 931-937 (2017).

70. Fedotova, Y. V. et al. Phosphinohydrazines and phosphinohydrazides $M(-N$ $\left.(\mathrm{R})-\mathrm{N}(\mathrm{R})-\mathrm{PPh}_{2}\right)_{\mathrm{n}}$ of some transition and main group metals: synthesis and characterization: Rearrangement of $\mathrm{Ph}_{2} \mathrm{P}-\mathrm{NR}-\mathrm{NR}$ - ligands into aminoiminophosphorane, $\mathrm{RN}=\mathrm{PPh}_{2}-\mathrm{NR}-$, and related chemistry. $J$. Organomet. Chem. 689, 3060-3074 (2004).

71. Andrez, J., Pécaut, J., Bayle, P.-A. \& Mazzanti, M. Tuning lanthanide reactivity towards small molecules with electron-rich siloxide ligands. Angew. Chem. Int. Ed. 53, 10448-10452 (2014).

72. Buser, U., Ess, C. H. \& Gerson, F. The radical anion of $(E)$-azobenzene revisited. Magn. Reson. Chem. 29, 721-725 (1991).

73. Sadler, J. L. \& Bard, A. J. Electrochemical reduction of aromatic azo compounds. J. Am. Chem. Soc. 90, 1979-1989 (1968).

74. Ashby, E. C., Gurumurthy, R. \& Ridlehuber, R. W. Investigation of the purity of alkali metal diphenylphosphides and their reactions with organic halides. Evidence for single electron transfer. J. Org. Chem. 58, 5832-5837 (1993).

75. Rossi, R. A., Pierini, A. B. \& Peñéñory, A. B. Nucleophilic substitution reactions by electron transfer. Chem. Rev. 103, 71-168 (2003).
76. Bangerter, B. W., Beatty, R. P., Kouba, J. K. \& Wreford, S. S. Coupling reactions of diorganophosphides with organic halides. Evidence for a oneelectron path. J. Org. Chem. 42, 3247-3251 (1977).

77. Ashby, E. C., Sun, X. \& Duff, J. L. Single electron transfer in nucleophilic aliphatic substitution. Evidence for single electron transfer in the reactions of 1-halonorbornanes with various nucleophiles. J. Org. Chem. 59, 1270-1278 (1994).

78. Ashby, E. C. \& Deshpande, A. K. Electron transfer in the reactions of geminal dihalides with $\mathrm{Ph}_{2} \mathrm{P}^{-}$. Evidence for the formation of a carbene intermediate from a radical precursor. J. Org. Chem. 60, 7117-7124 (1995).

79. Fullam, B. W., Mishra, S. P. \& Symons, M. C. R. Unstable intermediates. Part CXLIX. An electron spin resonance study of various phosphinyl radicals formed by solid-state radiolysis. J. Chem. Soc. Dalton Trans. 2145-2148 (1974).

80. Xu, L., Wang, Y.-C., Ma, W., Zhang, W.-X. \& Xi, Z. Mechanistic insights into $\mathrm{N}-\mathrm{N}$ bond cleavage in catalytic guanylation reactions between 1,2diarylhydrazines and carbodiimides. J. Org. Chem. 79, 12004-12009 (2014).

81. Wang, L., Ishida, A., Hashidoko, Y. \& Hashimoto, M. Dehydrogenation of the $\mathrm{NH}-\mathrm{NH}$ bond triggered by potassium tert-butoxide in liquid ammonia. Angew. Chem. Int. Ed. 56, 870-873 (2017).

\section{Acknowledgements}

We would like to thank Dr. Saurabh S. Chitnis and Dr. Marius I. Arz for helpful discussions. We thank Paul Lawrence, Tom Leman for their help on the low temperature NMR spectroscopy experiments. We also acknowledge the EPSRC National Electron Paramagnetic Resonance Spectroscopy Research Facility and Service, and Richard Procter of Prof. Michael Ingleson's group at University of Manchester for their assistance with EPR measurements. This work was supported by European Union for Marie Skłodowska-Curie Actions for L.W. (H2020-MSCA-IF-2015_701972) and V.T.A. (H2020-MSCA-IF-2016_748371). V.T.A. also is grateful to NSERC of Canada for a postdoctoral fellowship. I.M also thanks the government of Canada for a Canada 150 Research Chair and University of Bristol for support.

\section{Author contributions}

L.W., V.T.A., and I.M. conceived the project and designed the experiments. L.W. and V.T.A. performed the experiments and analysed the data. H.J. performed computational chemistry. V.T.A. performed X-ray crystallography. A.B. and D.C. performed EPR measurements and modelled EPR spectral data. L.W., V.T.A., H.J., and I.M. wrote the manuscript. All the authors discussed the results and commented on the manuscript. L.W. and V.T.A. share co-first authorship given their contributions indicated above.

\section{Additional information}

Supplementary Information accompanies this paper at https://doi.org/10.1038/s41467 019-09832-4.

Competing interests: The authors declare no competing interests.

Reprints and permission information is available online at http://npg.nature.com/ reprintsandpermissions/

Peer review information: Nature Communications thanks R Baker and the other anonymous reviewer(s) for their contribution to the peer review of this work. Peer reviewer reports are available.

Publisher's note: Springer Nature remains neutral with regard to jurisdictional claims in published maps and institutional affiliations.

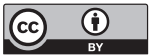

Open Access This article is licensed under a Creative Commons Attribution 4.0 International License, which permits use, sharing, adaptation, distribution and reproduction in any medium or format, as long as you give appropriate credit to the original author(s) and the source, provide a link to the Creative Commons license, and indicate if changes were made. The images or other third party material in this article are included in the article's Creative Commons license, unless indicated otherwise in a credit line to the material. If material is not included in the article's Creative Commons license and your intended use is not permitted by statutory regulation or exceeds the permitted use, you will need to obtain permission directly from the copyright holder. To view a copy of this license, visit http://creativecommons.org/ licenses/by/4.0/.

(c) The Author(s) 2019 